\title{
EMPRESAS TRANSNACIONAIS E INTERNALI- ZAÇÃO DE ATIVIDADES TECNOLÓGICAS NO COMPLEXO AGROINDUSTRIAL BRASILEIRO
}

\author{
Rosana do Carmo Nascimento ${ }^{1}$ \\ José Maria Alves da Silva
}

\begin{abstract}
Resumo - Esse trabalho objetiva investigar a contribuição das empresas transnacionais no processo de inovação tecnológica do Complexo Agroindustrial brasileiro. Para isso, construiu-se um índice de internalização relativa da atividade tecnológica (IRAT), a partir de informações de depósitos de patentes (invenção e modelo de utilidade) e registros de desenhos (desenhos e modelos industriais) no INPI. Foram analisados depósitos de 229 empresas, sendo 116 estrangeiras e 113 nacionais, agrupadas por setores específicos e segmentos do CAI. Observou-se elevada concentração de patentes nas empresas estrangeiras e baixa internalização tecnológica no Complexo, para as patentes de invenção $(0,061)$, e maior internalização nos modelos de utilidade e registros $(0,71)$. Considerando-se que os modelos de utilidade e registros têm teor tecnológico mais baixo, concluiu-se que é pouco significativa a contribuição das empresas transnacionais para a inovação tecnológica no CAI. Verificou-se maior internalização na agricultura do que no segmento a sua montante, que é mais sofisticado e intensivo no uso de tecnologias. Observou-se, também, que os setores de maior concentração de empresas estrangeiras apresentaram menores índices de internalização, e os de pequena participação, maiores índices de internalização tecnológica. Assim, conclui-se que a presença de empresas estrangeiras nos setores e segmentos do CAI está inversamente relacionada ao índice de internalização da atividade tecnológica.
\end{abstract}

Palavras-chave: Tecnologia, complexo agroindustrial, empresas transnacionais, patentes.

\footnotetext{
${ }^{1}$ Doutora em Economia Aplicada - Universidade Federal de Viçosa (MG), Professora da Faculdade de Ensino Superior de Rio Verde - FESURV - GO.

${ }^{2}$ Doutor em Economia - FEA - USP, Professor do Departamento de Economia Rural, Universidade Federal de Viçosa. CEP 36570-000 Viçosa - MG. E-mail: jmasilva@ufv.br.

Recebido em 02/10/2002 Aceito em 12/12/2002
} 


\section{Introdução}

\subsection{Tecnologia e desenvolvimento econômico}

Originalmente, o progresso econômico de uma nação dependia, essencialmente, da disponibilidade e da qualidade dos fatores primários de produção. Em decorrência da industrialização e da conseqüiente mecanização dos processos produtivos, o fator capital passou a ser preponderante e tão mais importante na explicação do desenvolvimento econômico quanto mais vinculado ao avanço tecnológico.

A forma como a inovação tecnológica é difundida e absorvida em um país determina o ritmo e a magnitude de seu progresso. A garantia de direitos de uso de tecnologia e propriedade intelectual condiciona o processo de geração e difusão das inovações entre países, o que explica a elevada concentração de tecnologia em pequenos números de empresas e nações, bem como o "hiato tecnológico" nos países em desenvolvimento.

O "hiato tecnológico" deve-se, fundamentalmente, às diferenças entre recursos técnicos, econômicos e financeiros das firmas transnacionais e das firmas locais, que, juntamente com o caráter monopolista do mecanismo patentário, permitem às empresas estrangeiras aumentar, cumulativamente, a dependência tecnológica dos países periféricos, limitando, em conseqüência, suas possibilidades de desenvolvimento autônomo.

O domínio tecnológico dessas empresas pode levá-las também a posições de monopólio quase absolutas, conforme destacado na literatura antitruste, o que, além de conseqüências econômicas negativas na sociedade, pode levar mesmo à estagnação tecnológica, por falta de concorrência.

Por outro lado, existem argumentos favoráveis à atuação das empresas transnacionais. Hymer (1978), por exemplo, destacou a contribuição dessas empresas para a integração da economia mundial. Segundo ele, as 
empresas transnacionais reduzem as imperfeições dos mercados, repartindo, de maneira eficaz, os produtos e fatores no mundo, quando tomam capital emprestado onde é mais barato e investem onde é mais produtivo, além de difundirem a técnica mais avançada via exportação de um país para todos os territórios em que opera.

Em razão da grande controvérsia acerca do papel das empresas transnacionais em seus mercados hospedeiros, novas investigações sobre esse assunto são sempre bem vindas, especialmente as que enfocam casos e experiências de países em situações particulares, como a do Brasil.

\subsection{Empresas transnacionais e internalização de tecnologia no Bra- sil}

As grandes empresas dos países desenvolvidos poderiam, em tese, dar grande contribuição para diminuir o hiato tecnológico entre as nações, caso investissem pesadamente em ciência e tecnologia fora de suas fronteiras nacionais. Entretanto, ao examinar os gastos com pesquisa e desenvolvimento $(\mathrm{P} \& \mathrm{D})$ realizados no Brasil, observa-se que isso está longe de acontecer.

Conforme indicado na Tabela 1, a participação média das empresas estrangeiras no total dos gastos em P\&D, no período de 1993 a 1998, foi muito modesta, se for levado em consideração o potencial dessas empresas. A participação média de apenas 17,5\%, nesse período, indica que essas empresas concentram os esforços inovativos em seus países de origem e exploram os direitos de patentes no exterior. 
Tabela 1 - Gastos das empresas com P\&D, por origem do capital, no Brasil - 1993 a 1998 (em US\$ 1000)

\begin{tabular}{cccccc}
\hline Ano & $\begin{array}{c}\text { Nacional } \\
(\mathrm{a})\end{array}$ & $\begin{array}{c}\text { Estrangeiro } \\
(\mathrm{b})\end{array}$ & Total (c) & $\begin{array}{c}\% \text { nacional } \\
(\mathrm{a} / \mathrm{c})\end{array}$ & $\begin{array}{c}\% \text { estrangeiro } \\
(\mathrm{b} / \mathrm{c})\end{array}$ \\
\hline & & & & & \\
1993 & 266.400 & 60.341 & 326.741 & 81,5 & 18,5 \\
1994 & 393.692 & 60.629 & 454.320 & 86,6 & 13,4 \\
1995 & 543.526 & 84.084 & 627.610 & 86,6 & 13,4 \\
1996 & 543.243 & 57.249 & 600.492 & 90,5 & 9,5 \\
1997 & 557.550 & 79.939 & 637.489 & 87,5 & 12,5 \\
1998 & 517.716 & 256.943 & 774.658 & 66,8 & 33,2 \\
Média & 470.354 & 99.864 & 570.218 & 82,5 & 17,5 \\
\hline
\end{tabular}

Fonte: ANPEI (2001).

De modo geral, o nível de investimentos em P\&D, no Brasil, é muito baixo, principalmente se comparado com o de países desenvolvidos. Em 1999, o dispêndio nacional em P\&D era equivalente a 0,87\% do PIB brasileiro, enquanto em países da OCDE observavam-se marcas muito maiores, como nos casos do Japão (3,1\%), EUA (2,7\%), Coréia do Sul $(2,5 \%)$ e Alemanha $(2,3 \%)$, por exemplo (Sociedade da Informação no Brasil - Livro Verde, 2001).

A conseqüência do baixo investimento em $\mathrm{P} \& \mathrm{D}$ é refletida nas estatísticas de patentes. Segundo Albuquerque e Macedo (1995), grande parte das patentes de invenção solicitada e concedida no Brasil pertence a não-residentes ${ }^{3}$. Isso explica bem a expressividade e a tendência crescente das remessas em contratos de transferência de tecnologia ${ }^{4}$ feitos pelo país, que, conforme indicado na Tabela 2, atingiram, em média, o equivalente a US\$1.010,7 milhão no período de 1993 a 1999.

\footnotetext{
${ }^{3}$ De um total de 2.649 patentes concedidas em 1993, 2.271 (cerca de 87\%) foram atribuídas a não-residentes, ou seja, pessoas físicas ou jurídicas que residem no exterior.

${ }^{4}$ Os contratos de tecnologia referem-se a marcas, patentes e franquias; fornecimento de tecnologia e serviços de assistência técnica; implantação de projetos e fornecimento de tecnologia, e serviços técnicos.
} 
Tabela 2 - Ingressos, remessas e balanço dos contratos de transferência de tecnologia no Brasil, em US\$ milhões - 1993 a 1999

\begin{tabular}{cccc}
\hline \multirow{2}{*}{ Ano } & \multicolumn{2}{c}{ Total de Contratos } & Balanço \\
\cline { 2 - 3 } & Ingressos & Remessas & \\
\hline 1993 & 118,7 & 186,2 & $-67,5$ \\
1994 & 207,5 & 296,4 & $-88,9$ \\
1995 & 270,7 & 599,8 & $-329,1$ \\
1996 & 410,4 & 886,5 & $-476,1$ \\
1997 & 687,8 & $1.255,3$ & $-567,5$ \\
1998 & $1.022,3$ & $1.985,4$ & $-963,1$ \\
1999 & 949,9 & $1.865,4$ & $-915,5$ \\
Total & $3.667,2$ & $7.074,6$ & $-3.407,4$ \\
Média anual & 523,9 & $1.010,7$ & $-486,8$ \\
\hline
\end{tabular}

Fonte: FAPESP (2001).

Além de gerar transferências ao exterior, o padrão de integração nos fluxos tecnológicos internacionais que as empresas transnacionais estabelecem no país é defasado em relação às tecnologias mais modernas. Ao investigar a internalização de atividades tecnológicas de empresas transnacionais, Albuquerque (2000) observou menor internalização em setores de tecnologia mais avançada, relativamente aos setores recursos-intensivos e de menor densidade tecnológica.

Essa discriminação entre os setores produtivos pode estar refletindo uma possível limitação do país em absorver tecnologias avançadas, mas pode, também, refletir uma particular estratégia adotada pelas empresas transnacionais de inserção na economia brasileira, com efeitos negativos sobre a economia do país, na medida em que contribui para aumentar contrastes já existentes entre os setores produtivos mais dinâmicos e os mais retardatários. A valer essa hipótese, tem-se mais um indício de que a contribuição do capital estrangeiro para o desenvolvimento dos setores produtivos nacionais seja menor do que costuma ser alardeado pelos arautos da globalização. 
Em razão da importância do Complexo Agroindustrial (CAI) para a economia brasileira e da expressividade do afluxo de capital estrangeiro a ele dirigido, é interessante investigar a relação entre os investimentos externos e o desenvolvimento tecnológico, enfocando os setores do CAI. Esse é o objetivo geral deste estudo. Especificamente, visa-se, por meio de uma análise da atividade de patenteamento das empresas, identificar o papel das corporações transnacionais no processo de inovação tecnológica.

A real participação das empresas estrangeiras na dinâmica tecnológica do sistema de inovação do Complexo Agroindustrial e, logicamente, sua contribuição para o desenvolvimento tecnológico do CAI podem ser inferidas a partir de estatísticas de patentes. Apesar de sua relevância, essa análise é muito pouco explorada no Brasil, conforme observou Albuquerque (op. cit.). No caso específico do CAI, não se constataram, até o presente momento, investigações dessa natureza, visando identificar o papel das empresas transnacionais que atuam no setor.

\section{Metodologia}

A legislação brasileira, mediante a Lei 9.279/96, permite classificar as patentes de acordo com seu conteúdo tecnológico e duração da proteção. Foram considerados, neste estudo, as patentes de invenção e modelo de utilidade e os registros de modelo e desenho industrial.

De acordo com a referida lei, também conhecida como "Lei de Patentes", uma patente de invenção deve atender aos requisitos de novidade, atividade inventiva e aplicação industrial, conforme artigo 8, podendo vigorar pelo prazo de 20 anos (artigo 40). As invenções são consideradas como patentes de conteúdo tecnológico mais elevado. As patentes de modelo de utilidade ou petty patents podem ser um objeto de uso prático, ou parte dele, que atenda ao requisito de aplicação industrial, devendo apresentar nova forma ou disposição, envolvendo ato inventivo que melhore a funcionalidade de seu uso ou de sua fabricação (artigo 9), 
podendo vigorar pelo prazo de 15 anos (artigo 40). O registro de desenho industrial, por sua vez, consiste na "forma plástica ornamental de um objeto, ou conjunto ornamental de linhas e cores que possa ser aplicado a um produto, proporcionando resultado visual novo e original na sua configuração externa e que possa servir de tipo de fabricação industrial" (artigo 95). O registro de desenho industrial vigora por 10 anos e pode ser prorrogado por cinco anos, três vezes sucessivas (artigo 108). Enquanto as invenções são consideradas como patentes de conteúdo tecnológico mais elevado, as patentes de modelo de utilidade e os registros de desenho industrial e modelo industrial possuem baixo teor tecnológico.

Com a "Lei de Patentes", o modelo industrial deixou de ser considerado uma patente, passando a ser protegido pelo Registro de Desenhos Industriais. Portanto, têm-se como patentes os modelos de utilidade e as invenções e, como registro de desenho, os desenhos e modelos industriais. Essa modificação aproximou a lei brasileira da grande maioria dos países, onde os modelos industriais são conhecidos sob o termo design.

Para identificar a origem da fonte de geração de tecnologia no país, analisou-se um conjunto de dados referentes à concessão de patentes a empresas residentes e não-residentes no Brasil. Foram selecionadas 116 empresas estrangeiras e 113 nacionais, agrupadas por setores específicos e segmentos do CAI, conforme publicação da Gazeta Mercantil (2002), Revistas Exame - Melhores e Maiores (2001) e Agroanalisys (2002) - As 100 Maiores Empresas do Agribusiness.

Estudos empíricos sobre a questão do desenvolvimento tecnológico e internacionalização de tecnologia se baseiam na análise das patentes concedidas pelo USPTO (US Patent and Trade Mark Office ). Esses dados são usados, como referência, para avaliar a contribuição do investimento estrangeiro à inovação tecnológica. Porém, essa metodologia não é aconselhada para países em desenvolvimento, como o Brasil, que possuem pequena participação nas redes internacionais de pesquisa. Tendo em vista que parte considerável das inovações desses países não é 
sofisticada o bastante para ser registrada junto ao USPTO, esse indicador acaba se tornando inadequado para captar sua dinâmica inovativa.

O método mais apropriado é a comparação entre residentes e não-residentes, se bem que limitado, uma vez que existem outros meios de difusão sem patenteamento externo, como é o caso do movimento de profissionais, exportações de bens e serviços, feiras industriais, viagens pessoais, intercâmbio de cartas, etc. Não obstante, as estatísticas de patentes constituem poderosa fonte de dados voltados para análise do processo de inovação tecnológica. Além disso, a comparação entre residentes e não-residentes, conforme proposto neste estudo, fornece uma informação a mais sobre a relação das empresas estrangeiras com o país hospedeiro, ao permitir medir a relação entre sua capacidade tecnológica e as atividades efetivamente internalizadas no país.

O índice de internalização relativa de atividade tecnológica (IRAT) das empresas transnacionais, conforme proposto por Albuquerque (2000), compara as patentes de residentes das subsidiárias com as patentes de não-residentes em suas matrizes, o que permite identificar a capacidade tecnológica da empresa transacional e o montante de atividades tecnológicas que ela efetivamente internaliza no país hospedeiro. Foram consideradas apenas as patentes de invenção e os modelos de utilidade depositadas no INPI e publicadas a partir de 1992. Ressalta-se, mais uma vez, que os dados utilizados referem-se somente aos depósitos realizados pelas empresas estrangeiras, não sendo contabilizados dados relativos às empresas nacionais. Esse índice é formado pela razão entre as patentes de residentes e não-residentes, ou seja,

$$
\text { IRAT }=\frac{\text { número de patentes de residentes }}{\text { número de patentes de não - residentes }} \text {. }
$$


A capacidade tecnológica da empresa transnacional é indicada pelas patentes de não-residentes, que refletem também a importância atribuída ao país em sua estratégia internacional, ou seja, indica a intenção da empresa em expandir a sua capacidade de produção naquele mercado, com mais ou menos modernização tecnológica. Por outro lado, as patentes de residentes das subsidiárias indicam o empenho da transnacional em investir em tecnologia no país hospedeiro. Portanto, mediante a comparação entre patentes de residentes e não-residentes, pode-se avaliar o grau de internalização tecnológica relativo à capacidade tecnológica da transnacional.

Outra interpretação possível dos valores do indicador de internalização diz respeito aos objetivos dos investimentos estrangeiros, com os quais se relacionam três objetivos ou formas de produção internacional, conforme Dunning (1988), quais sejam, a exploração de mercados locais ou market seeking; outro é a exploração de recursos locais ou resource seeking; os ganhos de eficiência ou efficiency seeking. Os investimentos que visam explorar mercados ou recursos, em geral, não requerem grandes esforços inovativos, razão pela qual devem estar associados a índices de internalização mais baixos. Por outro lado, investimentos que visam a ganhos de eficiência estariam associados a índices mais elevados, já que, via de regra, requerem maiores esforços inovativos.

\section{Resultados e discussão}

De um total de 17.764 patentes e registros de desenhos analisados, constatou-se o predomínio das patentes de invenção, com 91\% do total, enquanto os modelos de utilidade (MU) corresponderam a 2\%; os modelos industriais (MI), a 3\%; e os desenhos industriais (DI), a 4\%, conforme ilustrado na Figura 1. Considerando-se que as patentes de invenção são tecnologicamente superiores às demais, pode-se dizer, num primeiro momento, que o Complexo Agroindustrial é um setor produtivo que inova muito mais do que apenas adapta tecnologias já existentes. 

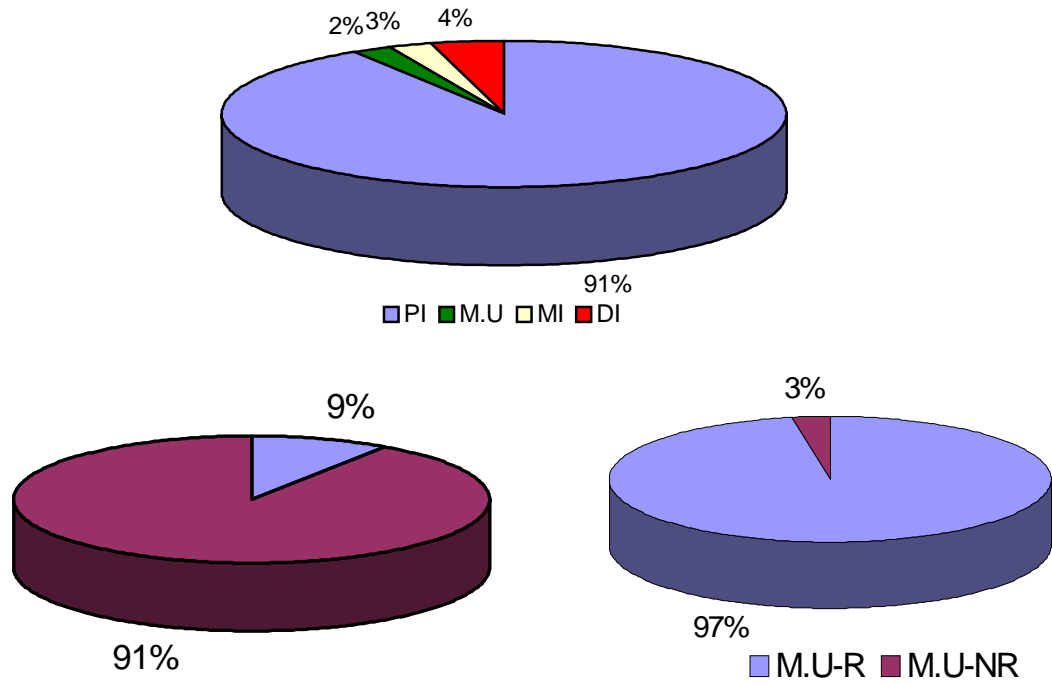

\section{$\square \mathrm{PI}-\mathrm{R} \square \mathrm{PI}-\mathrm{NR}$}

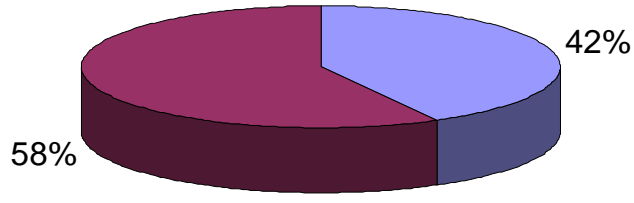

$\square \mathrm{DI}-\mathrm{R} \square \mathrm{DI}-\mathrm{NR}$

Figura 1 - Tipos de patentes e registros no CAI.

Fonte: Nascimento (2002).

No entanto, quando se analisa a origem dessas patentes e registros no CAI, verifica-se que grande parte pertence a não-residentes, principalmente as de invenção (Figura 2). 


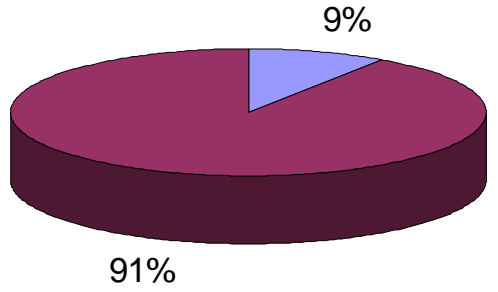

$\square \mathrm{PI}-\mathrm{R} \square \mathrm{PI}-\mathrm{NR}$

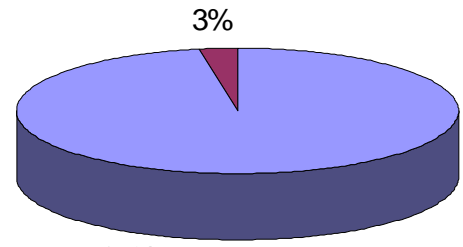

$97 \%$

$\square$ M.U-R $\square$ M.U-NR

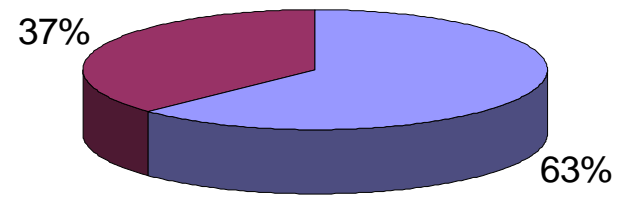

$\square \mathrm{MI}-\mathrm{R} \square \mathrm{MI}-\mathrm{NR}$

Figura 2 - Participação de residentes e não-residentes em patentes e registros.

Fonte: Nascimento (op. cit.).

Observa-se que a grande maioria das patentes mais importantes, ou seja, as de invenção, pertence a estrangeiros (91\%), e os residentes dominam apenas as de menor intensidade tecnológica, com 97\% dos modelos industriais. Entre os registros de desenhos, a distribuição foi mais equilibrada. Apesar de os residentes possuírem a maior parte dos depósitos desses registros (MI e DI), a participação de não-residentes é considerável; $37 \%$ nos modelos industriais e $42 \%$ nos desenhos industriais.

Com base nessas informações, cabe questionar a efetiva contribuição das empresas estrangeiras para a atividade de inovação tecnológica do CAI, ou melhor, quanto essas empresas internalizam de sua atividade tecnológica. 
Para isso, é preciso obter informações sobre o número de patentes de residentes e não-residentes depositadas pelas empresas transnacionais. Na Tabela 3, têm-se, para cada ano, os totais de patentes de invenção e o modelo de utilidade das empresas estrangeiras, registrados como residentes e não-residentes. Observa-se que, em 1990, as empresas estrangeiras que atuam no CAI brasileiro tinham registrado no INPI, como residentes, 24 patentes de invenção e 10 modelos de utilidade e, como não-residentes, 520 patentes de invenção e 4 modelos de utilidade.

Tabela 3 - Patentes de invenção e modelo de utilidade - residentes e nãoresidentes - detidos por empresas estrangeiras

\begin{tabular}{|c|c|c|c|c|c|}
\hline \multirow{2}{*}{ Ano } & \multicolumn{2}{|c|}{$\mathrm{PI}-\mathrm{MU}$} & \multirow{2}{*}{ Ano } & \multicolumn{2}{|c|}{ PI- MU } \\
\hline & Res & NRes & & Res & NRes \\
\hline 1980 & $64-1$ & $73-1$ & 1990 & $24-10$ & $520-4$ \\
\hline 1981 & $51-0$ & $71-0$ & 1991 & $38-8$ & $641-1$ \\
\hline 1982 & $18-3$ & $118-1$ & 1992 & $34-7$ & $645-0$ \\
\hline 1983 & $29-11$ & $113-1$ & 1993 & $28-8$ & $665-0$ \\
\hline 1984 & $18-3$ & $140-1$ & 1994 & $17-4$ & $747-0$ \\
\hline 1985 & $17-3$ & $202-0$ & 1995 & $37-3$ & $942-0$ \\
\hline 1986 & $9-2$ & $236-0$ & 1996 & $46-7$ & $1.270-0$ \\
\hline 1987 & $28-7$ & $282-1$ & 1997 & $70-4$ & $1.847-0$ \\
\hline 1988 & $16-11$ & $307-1$ & 1998 & $103-5$ & $1.747-0$ \\
\hline 1989 & $11-3$ & $393-0$ & 1999 & $41-6$ & $1.992-0$ \\
\hline & & & 2000 & $8-4$ & $924-0$ \\
\hline
\end{tabular}

Fonte: Nascimento (op. cit).

De acordo com os dados apresentados, verifica-se que os números, ao longo do período analisado (1980 a 2000), são crescentes para as patentes de invenção de não-residentes e praticamente estáveis para as patentes de invenção depositadas no Brasil como de residentes. Observase, ainda, baixa incidência de modelos de utilidade registrados como nãoresidentes, principalmente nos anos 90 . Esses dados foram utilizados no 
cálculo do índice de internalização relativa da atividade tecnológica (IRAT), cujos resultados estão apresentados na Tabela 4.

Tabela 4 - Internalização relativa da atividade tecnológica no CAI - 1980 a 2000

\begin{tabular}{cccc}
\hline Ano & IRAT & Ano & IRAT \\
\hline 1980 & 0,878 & 1990 & 0,065 \\
1981 & 0,718 & 1991 & 0,072 \\
1982 & 0,176 & 1992 & 0,064 \\
1983 & 0,350 & 1993 & 0,054 \\
1984 & 0,150 & 1994 & 0,028 \\
1985 & 0,099 & 1995 & 0,042 \\
1986 & 0,047 & 1996 & 0,042 \\
1987 & 0,124 & 1997 & 0,040 \\
1988 & 0,087 & 1998 & 0,062 \\
1989 & 0,036 & 1999 & 0,024 \\
Média & 0,27 & 2000 & 0,013 \\
\hline
\end{tabular}

Fonte: Nascimento (op. cit).

Considerou-se, para o cômputo anual das patentes, a data de depósito no INPI. Verifica-se que, no início dos anos 80, a internalização de tecnologia era elevada, porém com tendência altamente decrescente, conforme pode ser visualizado na Figura 3. 


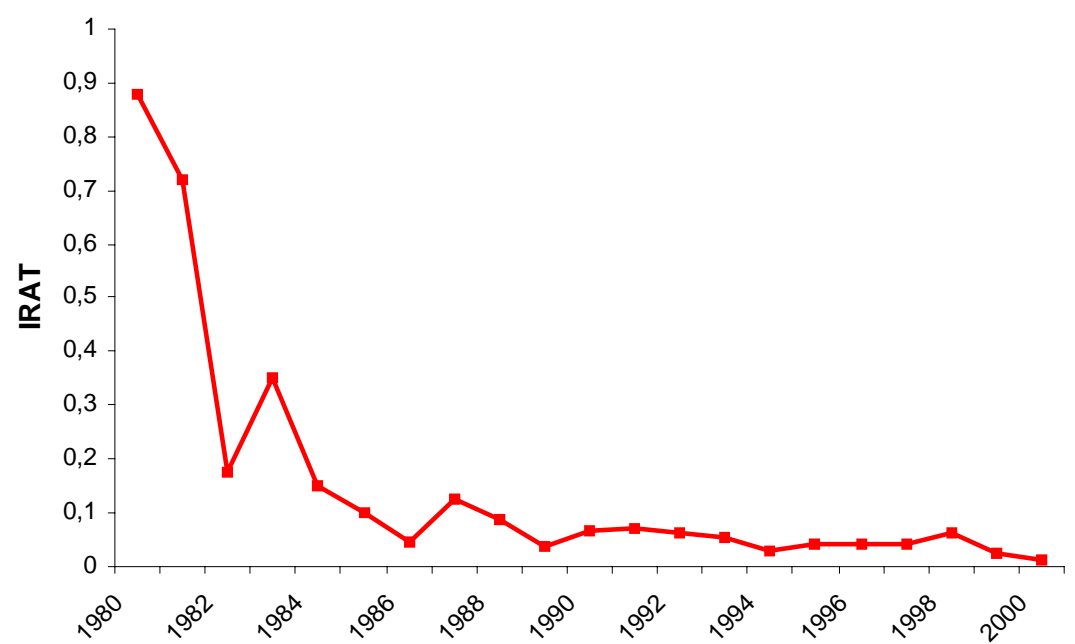

Figura 3 - Internalização relativa da atividade tecnológica no CAI - 1980 a 2000.

Nos anos 90, a internalização relativa mostrou-se mais estável, porém foi consideravelmente inferior ao apresentado na década anterior, com média de 0,046, nos anos 90, contra 0,27, nos anos 80. Apesar de se manter mais estável, a tendência ao longo de todo o período foi descrente. Em 2000, o índice apresentou o valor mínimo $(0,013)$, o que indica não haver perspectiva de mudança na orientação das empresas estrangeiras na geração e utilização de tecnologia no Brasil.

O acentuado declínio verificado nos anos 80, e a evolução do índice nos anos 90 podem ser bem visualizados na Figura 3. Observa-se que ao longo dos anos 80, com exceção dos anos de 1983 e 1987, a internalização de tecnologia mostrou-se fortemente decrescente. Ao longo dos anos 90, houve tendência de queda, porém mais suave.

Esse índice foi calculado, também, para o Complexo Agroindustrial agregado, para seus segmentos - montante, jusante e setor agrícola - e para os diversos setores que compõe o CAI (Tabela 5). Consideraram-se apenas as 
patentes de invenção para o cálculo do IRAT, pois alguns setores analisados não apresentaram dados sobre os demais tipos de patentes e registros.

Tabela 5 - Internalização relativa da atividade tecnológica nos setores e segmentos do CAI

\begin{tabular}{|c|c|c|c|c|}
\hline \multirow{2}{*}{ Setores } & \multirow{2}{*}{$\begin{array}{c}\mathrm{N} \cdot{ }^{\circ} \mathrm{de} \\
\text { empresas }\end{array}$} & \multicolumn{2}{|c|}{$\mathrm{PI}$} & \multirow{2}{*}{ IRAT } \\
\hline & & RES & NRES & \\
\hline Produtos veterinários e farmacêuticos & 23 & 125 & 6.089 & $\overline{0,021}$ \\
\hline Adubos e fertilizantes & 7 & 14 & 636 & 0,022 \\
\hline Máquina e equipamentos agrícolas & 7 & 18 & 39 & 0,462 \\
\hline Bombas e compressores & 5 & 11 & 26 & 0,423 \\
\hline Artigos de borracha & 3 & 215 & 1.220 & 0,176 \\
\hline Química e petroquímica & 24 & 377 & 5.330 & 0,071 \\
\hline Total a Montante & 69 & 760 & 13.340 & 0,057 \\
\hline Agricultura e pecuária & 3 & 0 & 37 & 0 \\
\hline Celulose e papel & 8 & 10 & 59 & 0,169 \\
\hline Total Agricultura & 11 & 10 & 96 & 0,104 \\
\hline Alimentos & 21 & 50 & 788 & 0,063 \\
\hline Bebidas e fumo & 9 & 39 & 223 & 0,175 \\
\hline Produtos de madeira & 2 & 9 & 6 & 1,5 \\
\hline Têxtil e couro & 2 & 7 & 121 & 0,058 \\
\hline Supermercado e embalagens & 2 & 12 & 25 & 0,48 \\
\hline Total a Jusante & 36 & 117 & 1.163 & 0,101 \\
\hline Total do Complexo & 116 & 887 & 14.599 & 0,061 \\
\hline
\end{tabular}

Fonte: Nascimento (op. cit).

Em relação aos segmentos, é possível perceber que a agricultura, que é relativamente um setor de baixa tecnologia e recurso intensivo, foi o que mais internalizou tecnologia, apresentando maior índice que o verificado no Complexo como um todo $(0,104)$. Esse resultado é influenciado, em grande parte, pelos dados das empresas de papel e celulose. $\mathrm{O}$ menor índice foi apresentado pelo setor a montante $(0,057)$, justamente o segmento mais intensivo no uso de tecnologia, portanto, mais sofisticado, conforme visto anteriormente. A jusante, apresentou internalização de 0,1, acima da verificada no conjunto do CAI, que foi de 0,061.

Considerando-se os setores individualmente, observa-se que a grande maioria apresentou índice de internalização inferior à média observada no complexo como um todo. Nos setores que fazem parte da montante do complexo, apenas no setor de química e petroquímica verificou-se 
maior internalização $(0,071)$ que a média do Complexo agregado.

Os setores de agricultura e pecuária foram considerados conjuntamente, devido à baixa participação de empresas estrangeiras (apenas três Aventis Cropscience, Asgrow e Swift Armour); apesar disso, apresentaram internalização igual a zero, ou seja, nenhuma patente dessas empresas foi registrada no Brasil, como residente, em nome da subsidiária brasileira. Os menores índices, no entanto, foram encontrados nos setores de Produtos Veterinários e Farmacêuticos, cujos IRAT foram iguais a 0,021, e Adubos e Fertilizantes, cujo IRAT foi igual a 0,022. Os maiores índices de internalização ocorreram nos setores de supermercados e embalagens $(0,48)$ e máquinas e equipamentos agrícolas $(0,46)$.

Ressalta-se, ainda, elevada concentração de empresas estrangeiras nos setores, a montante do complexo. Existem 69 empresas estrangeiras a montante, das quais estão 11 no setor agrícola; e 36 a jusante. Observa-se, nos setores destacados, que apenas três apresentaram mais de vinte empresas estrangeiras, quais sejam, produtos veterinários e farmacêuticos (23 empresas), química e petroquímica (24 empresas) e alimentos (21 empresas). Nos demais, o número nunca foi superior a 8. Curiosamente, justamente nos setores onde a presença de empresas estrangeiras é maior, constataram-se os menores índices de internalização, e vice-versa, o que indica associação negativa entre a concentração setorial de empresas estrangeiras e o índice de internalização relativa da atividade tecnológica.

Calculou-se, também, o IRAT baseado nos modelos de utilidade, nos modelos industriais e nos desenhos industriais, conjuntamente, para o complexo agregado. Este índice foi bem maior $(0,71)$ que o apresentado na Tabela 5, calculado com base nas patentes de invenção $(0,061)$, o que reflete o incipiente esforço inovativo das empresas estrangeiras no Brasil, que pouco contribuíram para o processo de inovação tecnológica, pois essas patentes e registros referem-se à tecnologias menos sofisticadas, conforme descrito anteriormente.

Esses resultados estão muito próximos aos encontrados por Albuquerque (op. cit. ) que analisou a internalização relativa da atividade tecnológica 
no conjunto das 368 maiores corporações globais presentes no Brasil, cujo IRAT foi igual a 0,064, e para as 100 maiores transnacionais, cujo IRAT foi igual a 0,071 . Percebe-se, portanto, que o índice médio encontrado para o CAI, neste estudo, não difere significativamente da média nacional, considerando-se o conjunto das 368 maiores corporações.

Segundo Albuquerque (op. cit), esses valores indicam um desequilíbrio entre a contribuição potencial e a real das empresas estrangeiras na dinâmica do sistema de inovação tecnológica no Brasil. Considerandose a atuação das empresas estrangeiras, nos vários setores produtivos do país, pode-se dizer que a contribuição para o processo de inovação tecnológica está muito aquém de suas reais possibilidades.

É preciso salientar, ainda, que as empresas que atuam no complexo agroindustrial caracterizam-se pela utilização de tecnologias destinadas, essencialmente, à produção de bens de consumo, pela própria natureza do CAI, diferindo, portanto, de outras empresas estrangeiras que atuam em setores mais dinâmicos. Assim, os benefícios advindo das empresas estrangeiras nesse setor são limitados não apenas pelas estratégias utilizadas por elas, como também por se tratar de um setor relativamente pouco intensivo em tecnologia, que, em grande parte, contribui para o aprofundamento do déficit tecnológico do país. Essas características devem ser levadas em consideração na formulação de políticas de incentivo à inovação que envolvam capital estrangeiro no Brasil.

\section{Conclusões}

Com o objetivo de analisar a contribuição do investimento estrangeiro para a atividade de inovação tecnológica do Complexo Agroindustrial brasileiro, buscou-se avaliar, quantitativamente e qualitativamente, as patentes e registros de desenhos depositados no INPI, no período de 1992 a 2002, pelas diversas empresas que atuam no CAI. A motivação central foi identificar a contribuição das empresas estrangeiras para o processo de inovação tecnológico. 
A análise das 17.764 patentes e registros de desenhos pertencentes a 229 empresas nacionais e estrangeiras do Complexo Agroindustrial permitiu constatar que as tecnologias de ponta não são registradas em nome das subsidiárias brasileiras, dado o predomínio de patentes de invenção (alto teor tecnológico) de não-residentes, ou seja, patentes registradas em nome de pessoas físicas ou jurídicas no exterior.

A pequena participação das patentes de residentes no total das patentes do CAI expressa a reduzida contribuição das empresas, nacionais e estrangeiras, à realização de um processo autônomo de inovação tecnológica. Como as empresas estrangeiras, responsáveis pela maior parte das inovações do setor, registraram muito pouco de suas invenções no país, limitaram-se, consideravelmente, os benefícios do setor do agronegócio para o desenvolvimento sustentável da economia. Percebeu-se que o progresso tecnológico do CAI está concentrado nas ações dos grandes grupos estrangeiros.

A baixa atividade de inovação tecnológica, verificada no CAI, foi associada ao limitado esforço de inovação tecnológica da iniciativa privada, constatada pela pequena participação nos dispêndios do país com P\&D. Por isso, as empresas brasileiras despender mais esforços de investimento em Pesquisa e Desenvolvimento (P\&D) para melhorar a atividade de patenteamento do país, aumentar sua autonomia no processo produtivo, no produto final, nos bens e serviços e, conseqüentemente, reduzir as transferências de recursos ao exterior na forma de pagamentos de royalties. Nesse sentido, poderiam ser implementadas ações governamentais articuladas num plano estratégico em ciência e tecnologia.

O índice de internalização relativa da atividade tecnológica (IRAT), no CAI, confirmou a hipótese de pouco envolvimento das empresas estrangeiras no processo interno de inovações tecnológicas do Brasil. Percebeuse que a internalização de tecnologia, na década de 80 , foi maior que a dos anos 90. Em 2000, o índice apresentou valor mais baixo, o que indica que 
não há perspectiva de mudança na orientação das empresas estrangeiras no que se refere à geração e utilização de tecnologia no país. Em relação à internalização nos diferentes segmentos, foi possível perceber que os setores mais intensivos no uso de tecnologia foram os que menos internalizaram, enquanto que o setor agrícola, apresentou o maior índice, em relação ao verificado no Complexo como um todo. Há de se destacar, entretanto, que, conforme indicado na Tabela 5, isso se deveu, exclusivamente, à inclusão no setor agrícola de empresas no ramo de papel e celulose. ${ }^{5}$

Os setores de produtos veterinários e farmacêuticos foram os que apresentaram os menores índices. De modo geral, nos setores onde a concentração de empresas estrangeiras era alta, houve baixa internalização de tecnologia. e nos setores onde as empresas estrangeiras estavam presentes em menor quantidade, essa internalização foi relativamente alta. Concluiu-se que a presença setorial de empresas estrangeiras está inversamente associada ao índice de internalização relativa da atividade tecnológica.

Esses resultados indicam a existência de um desequilíbrio entre contribuição potencial e contribuição real das empresas estrangeiras à dinâmica do sistema de inovação tecnológico do CAI. Considerando-se a abrangente atuação das empresas estrangeiras e o domínio que exercem sobre vários setores produtivos no Brasil, conclui-se que a contribuição destas para o processo de inovação tecnológica do país está muito aquém de suas reais possibilidades. Essa situação tende a permanecer assim, ou piorar, enquanto não houver no país políticas industriais bem articuladas com as áreas de ciência e tecnologia e, sobretudo, decisivamente comprometidas com o interesse nacional.

\footnotetext{
${ }^{5}$ As empresas desse ramo, que internalizaram tecnologia, foram Arjo Wiggins, Enso, Igaras, Internacional Paper, Kymmene, Rigesa, Schweitzer Mauduit e Stora.
} 


\section{Referências Bibliográficas}

ALBUQUERQUE, E.M., MACEDO, P.B.R. Patentes de invenção concedidas a residentes no Brasil: indicações da eficiência dos gastos em pesquisa e desenvolvimento. Pesquisa e Planejamento Econômico, Rio de Janeiro, V. 25, n. 3, p. 541-558, 1995.

ALBUQUERQUE, E.M. Empresas transnacionais e suas patentes no Brasil: resultados iniciais de uma investigação sobre a internalização de atividades tecnológicas. Belo Horizonte: CEDEPLAR/FACE-UFMG, 2000. (mimeo).

DUNNING, J.H. Explaining international production. London: Harper Collins Academic, 1988.

HYMER, S. Empresas multinacionais: a internacionalização do capital. Tradução: TEIXEIRA, A. Rio de janeiro: GRAAL, 1978.

BRASIL. Congresso Nacional. Lei 9.279, de 14 de maio de 1996. Disciplina os direitos e obrigações referentes à propriedade industrial. Brasília, 1996.

NASCIMENTO, R.C. Capital estrangeiro e inovação tecnológica no complexo agroind ustrial brasileiro. Viçosa, MG: UFV, 2003. Tese (Doutorado em Economia Aplicada) - Universidade Federal de Viçosa, 2003. 